2018-02

Three-dimensional dynamics of baroclinic tides over a seamount

\author{
Vlasenko, Vasyl
}

http://hdl.handle.net/10026.1/10845

10.1002/2017JC013287

Journal of Geophysical Research: Oceans

American Geophysical Union

All content in PEARL is protected by copyright law. Author manuscripts are made available in accordance with publisher policies. Please cite only the published version using the details provided on the item record or document. In the absence of an open licence (e.g. Creative Commons), permissions for further reuse of content should be sought from the publisher or author. 


\section{Three-dimensional dynamics of baroclinic tides over a seamount}

Vasiliy Vlasenko ${ }^{1}$, Nataliya Stashchuk ${ }^{1}$, and W. Alex M. Nimmo-Smith ${ }^{1}$

Vasiliy Vlasenko, School of Biological and Marine Sciences, Plymouth University, Plymouth, PL4 8AA, UK (vvlasenko@plymouth.ac.uk)

${ }^{1}$ School of Biological and Marine Sciences,

Plymouth University, Plymouth, PL4 8AA, UK. 


\section{Abstract.}

2 The Massachusetts Institute of Technology general circulation model is used

3 for the analysis of baroclinic tides over Anton Dohrn Seamount (ADS), in

${ }_{4}$ the North Atlantic. The model output is validated against in-situ data col-

5 lected during the 136-th cruise of the RRS "James Cook" in May-June 2016.

6 The observational data set includes velocity time series recorded at two moor-

7 ings as well as temperature, salinity and velocity profiles collected at 22 hy-

s drological stations. Synthesis of observational and model data enabled the

9 reconstruction of the details of baroclinic tidal dynamics over ADS. It was

${ }_{10}$ found that the baroclinic tidal waves are generated in the form of tidal beams

${ }_{11}$ radiating from the ADS periphery to its centre, focusing tidal energy in a

${ }_{12}$ surface layer over the seamount's summit. This energy focusing enhances sub-

${ }_{13}$ surface water mixing and the local generation of internal waves. The tidal

${ }_{14}$ beams interacting with the seasonal pycnocline generate short-scale inter-

15 nal waves radiating from the ADS centre. An important ecological outcome

${ }_{16}$ from this study concerns the pattern of residual currents generated by tides.

${ }_{17}$ The rectified flows over ADS have the form of a pair of dipoles, cyclonic and

${ }_{18}$ anti-cyclonic eddies located at the seamount's periphery. These eddies are

${ }_{19}$ potentially an important factor in local larvae dispersion and their escape

${ }_{20}$ from ADS. 


\section{Introduction}

21

22

29

39 Trough. This seamount, or table-mount guyot, is a former volcano with nearly circular

40 shape and about $40 \mathrm{~km}$ in diameter, Figure 1 . ADS rises approximately $1800 \mathrm{~m}$ above the

${ }_{41}$ bottom with minimum depth in its centre of about $530 \mathrm{~m}$. 
${ }_{42}$ A large number of theoretical and experimental papers have been published on dynam-

${ }_{43}$ ical processes over seamounts, e.g barotropic and baroclinic tides, generation of internal

${ }_{44}$ waves, mixing, response to stationary currents, formation of residual circulation, eddies,

45 etc. An overview of the most significant publications can be found in Vlasenko et al.

${ }_{46}$ [2013]. The primary goal of the present paper is to report a new set of observational data

${ }_{47}$ collected during JC136 near ADS. These data were used for setting a numerical model

${ }_{48}$ and its further validation. An overall goal of these model efforts was to investigate the

49 tidal regime around ADS that took place during the JC136 cruise. The comprehensive

so model output allowed us to build up a complete picture of possible motions developing

${ }_{51}$ in the area, specifically, baroclinic tidal energy focusing over the bank, local generation

${ }_{52}$ of internal waves due to interaction of tidal beams with the seasonal pycnocline, and the

53 generation of residual currents and their possible implication for larvae dispersion.

${ }_{54}$ The paper is organised as follows. The measurement techniques and collected data are

${ }_{55}$ presented in Section 2, along with the model set-up. The next section reports the effect

${ }_{56}$ of the focusing of baroclinic tidal energy over the ADS summit. The mechanism of local

57 generation of internal waves is discussed in Section 4. Tidally generated residual currents

58 and their possible implications for larvae dispersion are analysed in Section 5. Finally,

${ }_{59}$ Section 6 summarises all principal findings.

\section{Measurements and model set up}

\subsection{Observational data set}

60 Figure 1 shows the scheme of the field experiment conducted on JC136 cruise. The ${ }_{61}$ observational campaign included 18 CTD stations, deployment of two moorings, M1 and ${ }_{62} \mathrm{M} 2$, and four dives of the ROV ISIS. Note that CTD stations 4-19 located at the edge of 
${ }_{63}$ steep topography were repeated at the same site (yo-yo) on 19th May 2016 when ROV

${ }_{64}$ dives were suspended due to bad weather conditions. At the end of the cruise (on 17th

${ }_{65}$ June 2016) three CTD stations, 41-43, were conducted along the cross-bank transect

${ }_{66}$ shown in Figure 1. A Lowered Acoustic Doppler Current Profiler (LADCP) was mounted

${ }_{67}$ at the CTD rosette, so vertical profiles of horizontal velocities were recorded at each

${ }_{68}$ station. The obtained data were processed with the LDEO LADCP Processing Software

69 developed by Visbeck [2002].

70 Moorings M1 and M2 were equipped with an upward-looking $75 \mathrm{kHz}$ Acoustic Doppler ${ }_{71}$ Current Profilers (ADCP) and a $600 \mathrm{KHz}$ downward-looking ADCP for measuring the 72 flow regime in the bottom boundary layer. Details of moorings instruments are provided ${ }_{73}$ in Table 1 . Table 2 shows the coordinates of ROV dives 270, 271, 272, and 292 that were ${ }_{74}$ used for modelling larvae dispersion. The collected data set was complemented with a 75 velocity time series recorded by a vessel mounted ADCP $(150 \mathrm{kHz})$ during ROV dive 296.

\subsection{The model}

${ }_{76}$ The fully nonlinear nonhydrostatic Massachusetts Institute of Technology general circu77 lation model (MITgcm, Marshall et al. [1997]) was used for modelling the wave dynamics ${ }_{78}$ near $\mathrm{ADS}$. The semi-diurnal $\mathrm{M}_{2}$ tidal harmonics predominates in the area [Egbert and ${ }_{79}$ Erofeeva, 2002], so we restricted our analysis by considering only this tidal constituent.

so The tidal forcing was activated in the model using an external software package added ${ }_{81}$ to the MITgcm code that sets a tidal potential in the RHS of the momentum balance ${ }_{82}$ equations. Two tidal components were introduced as follows [Stashchuk et al., 2017]

$$
U=A \sin (\omega t+\phi), \quad V=B \sin (\omega t)
$$


${ }_{84}$ where $U$ and $V$ are zonal and meridional water discharge, respectively, $\omega$ is the tidal

${ }_{85}$ frequency, and $\phi$ is the phase lag that controls the tidal ellipse inclination. The main part

${ }_{86}$ of the field campaign was conducted during the transition from neap to spring tide, so for

${ }_{87}$ setting the tide in the model we used $A=50 \mathrm{~m}^{2} \mathrm{~s}^{-1}, B=100 \mathrm{~m}^{2} \mathrm{~s}^{-1}$, and $\phi=\pi / 4.1$, which

88 provides a good coincidence with the ellipses of the inverse tidal model TPXO8.1 [Egbert

s9 and Erofeeva, 2002], Figure 2 a. A non-slip boundary condition was used at the bottom.

${ }_{90} \quad$ The model domain included $768 \times 794$ grid points. Its central part with $512 \times 538$ grid

${ }_{91}$ points and horizontal resolution $\Delta x=\Delta y=115 \mathrm{~m}$ was used for the analysis. The lateral

${ }_{92}$ grid areas that included 118 grid points were added at each side of the model domain. Here

93 the grid step was increased telescopically from $115 \mathrm{~m}$ in the central part to $5500 \mathrm{~m}$ towards

${ }_{94}$ the boundaries. Such a grid stretching allows one to radiate internal waves from the central

${ }_{95}$ area without their backward reflection from the boundaries. Another 10 boundary steps

${ }_{96}$ of the model domain at the periphery were added to release the barotropic tidal waves

${ }_{97}$ from the area. Here the grid step increased to $2 \cdot 10^{8} \mathrm{~m}$ at the model boundary. Such

98 a combination of a two-step telescopic grids eliminates reflection of both barotropic and

99 internal waves from the outer boundaries during the ten days of the numerical experiment.

${ }_{100}$ The vertical grid step was $\Delta z=10 \mathrm{~m}$ which provided quite a detailed resolution of tidally

101 induced baroclinic fields. The fluid stratification was taken from CTD data recorded at station 1 . The buoyancy frequency profile (blue line) is shown in Figure $2 \mathrm{~b}$ together with

103 the smoothed profile (the red line).

${ }_{104}$ The coefficients of horizontal viscosity were taken at the level of $10^{-2} \mathrm{~m}^{2} \mathrm{~s}^{-1}$. The ${ }_{105}$ vertical turbulent closure for the coefficients of vertical viscosity $\nu$ and diffusivity $\kappa$ was provided by the Richardson number dependent parametrisation, [Pacanowski and Philan- 
${ }_{112}$ background parameters, $\nu_{0}=1.5 \cdot 10^{-2} \mathrm{~m}^{2} \mathrm{~s}^{-1}, \mu=5$ and $n=1$ are the adjustable parameters.

${ }_{113}$ Such a parametrisation increases coefficients $\nu$ and $\kappa$ in the areas where the Richardson

114 number is small to take into account the mixing processes induced by shear instabilities

${ }_{115}$ and breaking internal waves. A systematic analysis of the sensitivity of the model output ${ }_{116}$ to the parameters $\nu_{b}, \kappa_{b}, \nu_{0}, \mu$, and $n$ was conducted in [Stashchuk and Hutter, 2001].

${ }_{117}$ It was found that with the above mentioned parameters formula (2) keeps the diffusivity ${ }_{118}$ and viscosity at the level sufficient for the model stability. On the other hand, this level ${ }_{119}$ of mixing and viscosity does not affect substantially the internal wave fields.

\section{Tidal beams and energy focusing}

We start our analysis with consideration of the velocity profiles recorded at CTD stations 41-43, Figure 1. The vertical profiles of instantaneous horizontal velocity $\sqrt{u^{2}+v^{2}}$ are shown in Figures $3 \mathrm{a}, 3 \mathrm{~b}$, and $3 \mathrm{c}$ by thick lines. These profiles clearly show evidence of local velocity maxima located at different depths at stations 41-43. Specifically, Figure 3 a, shows intensification of the surface currents at $100 \mathrm{~m}$ depth at station 43 , just over the top of ADS. The deepest maximum was recorded at $750 \mathrm{~m}$ depth at station 41 conducted at the bank edge, Figure $3 \mathrm{c}$. In between, at station 42 , the maximum of horizontal velocity was found in the intermediate layer at $330 \mathrm{~m}$ depth, Figure $3 \mathrm{~b}$. 
A series of model-based sampling was arranged in a similar way to the observations, i.e. at the positions of CTD stations 41-43. Twelve vertical profiles of $\sqrt{u^{2}+v^{2}}$ spanning the CTD sampling time (an approximate duration of CTD samplings in the cruise was one hour) with 5-min time interval are shown in Figures $3 \mathrm{a}, 3 \mathrm{~b}$, and $3 \mathrm{c}$ by thin light lines. Comparison of $\sqrt{u^{2}+v^{2}}$ profiles reveals that the positions of the extrema of the observed and model predicted profiles coincide. The level of theoretical and experimental amplitude velocities in these layers is also in a good agreement except probably the surface $200 \mathrm{~m}$ layer at station 43 . The $50-100 \%$ inconsistency between theoretical and experimental profiles visible in the surface layer in Figures 3 a could be a consequence of a surface current that existed in the area during the field experiment, but which was not set in the model because of the lack of the observational data for its validation. Another reason for the reported inconsistency could be imperfection of the LADCP processing procedure [Visbeck, 2002] which underestimates currents near sea surface. This issue was discussed by Aleinik et al. [2007] who showed that the error in the velocity in the surface layer can be as large as $0.06-0.08 \mathrm{~m} \mathrm{~s}^{-1}$. Thus, taking into account this reasoning one can conclude that the model reproduces the wave dynamics in the ADS area correctly.

The reason for the reported velocity maxima at different depths can be explained by considering the spatial distribution of the amplitude of the horizontal velocities $\sqrt{u^{2}+v^{2}}$ over one tidal cycle which is shown in Figure $3 \mathrm{~d}$ for the transect a-a (see Figure 1 ). This figure reveals evidence of two tidal beams generated at the sharp edges of the bank topography (at points A and B). They propagate upward and meet at the centre of the bank in the subsurface $200 \mathrm{~m}$ layer. The tidal-beam (or T-beam) interpretation of Figure 
${ }_{150} 3 \mathrm{~d}$ is confirmed by the positions of the curves

151

$$
\int \frac{d z}{\alpha(z)}= \pm x+\text { const }, \quad \alpha(z)=\sqrt{\frac{\omega^{2}-f^{2}}{N^{2}(z)-\omega^{2}}},
$$

shown in Figure $3 \mathrm{~d}$ by dashed lines. In this equation $x$ and $z$ are horizontal and vertical coordinates, $f$ is the Coriolis parameter, and $N(z)$ is the buoyancy frequency. In fact, dashed contours in Figure $3 \mathrm{~d}$ are the characteristic lines of the wave equation

$$
w_{x x}-\alpha^{2}(z) w_{z z}=0,
$$

where $w$ is the vertical wave velocity. Coincidence of these lines with zones of velocity maxima confirms a T-beam origin of the latter.

ADS is a circular guyot, Figure 1. One can assume that the T-beam mechanism of generation of internal waves works also in all other cross-sections around ADS (a similar case was considered by Baines [2007] for a symmetrical cylindrical seamount). As a result of the seamount symmetry, the tidal energy propagating from many sites at the bank periphery to its centre focuses over the top of ADS where station 43 was located. From theoretical predictions a large area of high concentration of tidal energy should be expected just over the seamount summit, which is obviously evident in Figure $3 \mathrm{~d}$ in the surface $200 \mathrm{~m}$ layer.

Additional observational evidence of the T-beam generation can be found in the mooring time series. According to Figure $3 \mathrm{~d}$, both moorings, M1 and M2, were deployed in the area where the T-beam could be recorded as a strong amplification of horizontal velocities at depths around $800 \mathrm{~m}$. In other words, the tidal beam should be seen in the moorings velocity time series, as well. Figures $4 \mathrm{a}$ and $4 \mathrm{c}$ clearly show intensification of zonal and meridional velocities in the bottom layer, specifically, below $700 \mathrm{~m}$ depth for mooring M1. 
${ }_{172}$ The model time series were recorded with a $20 \mathrm{~s}$ time interval at the position of mooring

${ }_{173}$ M1. They are presented in Figures $4 \mathrm{~b}$ (zonal velocity) and $4 \mathrm{~d}$ (meridional velocity).

${ }_{174}$ Comparison of the left and right patterns in Figure 4 shows their consistency.

${ }_{175}$ Similar time series recorded at mooring M2 and reproduced numerically for the same ${ }_{176}$ time span are shown in Figure 5. The model predicts that the position of the tidal beam 177 at this mooring should be at depths between $800 \mathrm{~m}$ and $1000 \mathrm{~m}$, Figure $3 \mathrm{~d}$. Figure 5 ${ }_{178}$ demonstrates intensification of the tidal velocity in this layer, both in observational and 179 model time series. The only difference between moorings M1 and M2 is that the latter 180 was deployed deeper than M1, i.e. at the $1200 \mathrm{~m}$ isobath. According to the tidal beam ${ }_{181}$ position shown in Figure 3 d, no substantial currents at mooring M2 below $1000 \mathrm{~m}$ depth ${ }_{182}$ are expected. This is exactly what Figure 5 demonstrates, both in observations and in 183 the model predictions.

${ }_{184}$ Analysis of the mooring data can be complemented by considering vertical oscillations. ${ }_{185}$ Figure 6 presents vertical velocities recorded at both moorings, M1 and M2, and predicted ${ }_{186}$ by the model. This figure reveals tidal periodicity which is clearly visible in the mooring ${ }_{187}$ M2 time series (panel c). This strong tidal signal recorded in the $700-1000 \mathrm{~m}$ layer is 188 associated with the tidal beam discussed above. In addition to that, one can identify 189 also a large number of positive and negative short-term pulses. They are present both in observational and model time series and cover a large part of the water column. Joint analysis of vertical velocities with model predicted temperature time series presented in

${ }_{192}$ Figures $6 \mathrm{~b}$ and $6 \mathrm{~d}$ by black solid lines (isotherms are shown with $0.2^{\circ}$ interval) reveals a ${ }_{193}$ strong correlation of short-term pulses evident in velocity records with vertical displace- 
${ }_{217}$ conclude that recorded variability of the temperature profiles in this layer (visible also in

\section{Mechanisms of generation of internal waves}

\subsection{Local generation of internal waves}


${ }_{237}$ maxima of the internal body force (IBF). In a two-dimensional $(x, z)$ case the IBF is:

${ }_{238} \quad \mathrm{IBF}=\rho_{0} u_{\text {tide }} H(x) z \frac{N^{2}(z)}{\omega}\left[\frac{1}{H(x)}\right]_{x}$.

${ }_{239}$ Here $u_{\text {tide }}$ is the amplitude of the barotropic tidal current; $H(x)$ is the bottom profile;

${ }_{240} \rho_{0}$ is the mean density. In our case, the spatial distribution of the IBF in the meridional ${ }_{241}$ across-bank section is presented in Figure 9 a.

It is clear from the IBF normalized distribution that the maximum of tidal energy ${ }_{243}$ conversion (generation of internal tides) should take place over the seamount's flanks, ${ }_{244}$ specifically, in the areas with centres $57.23^{\circ} \mathrm{N}$ at the south and $57.62^{\circ} \mathrm{N}$ at the north of ${ }_{245}$ ADS. Note that the latitude $57.62^{\circ} \mathrm{N}$ is located just between moorings M1 and M2. Thus, assuming the generation of the short period wave packets recorded during the ROV's dive 296 (shown in Figure 8), specifically in the area of the IBF maximum, these packets should

${ }_{248}$ propagate in opposite directions at moorings M1 and M2. However, according to Figures

${ }_{249} 8 \mathrm{~b}$ and $8 \mathrm{~d}$, they propagate in the same direction, i.e. northward. Taking into account a ${ }_{250}$ one-hour time lag between arrival of the waves at moorings M1 and M2, Figures $8 \mathrm{~b}$ and ${ }_{251} 8 \mathrm{~d}$, these waves should propagate from somewhere near the bank summit. Based solely ${ }_{252}$ on the distance between the moorings and the recorded time lag one can estimate the ${ }_{253}$ horizontal phase speed of the packet as $c=0.74 \mathrm{~m} \mathrm{~s}^{-1}$ which looks quite realistic for the considered area (see also estimates below).

\subsection{Lee wave mechanism}

Another possible scenario for short-period waves generation could be a lee-wave mechanism, which usually takes place near abrupt changes of bottom topography. Specifically, internal lee waves are generated downstream of the bottom topography by a strong su- 
${ }_{258}$ percritical tidal flow. They are released and propagate upstream when tidal flow slackens.

${ }_{259}$ The feasibility of lee wave generation appears when the Froude number, $\mathrm{Fr}=u_{\text {tide }} / c$, is ${ }_{260}$ equal to or larger than 1 . The phase speed $c$ of internal lee waves is calculated from the ${ }_{261}$ boundary value problem (BVP) for short-scale internal waves [Vlasenko et al., 2005]

$$
\Phi_{z z}+\frac{N^{2}(z)}{c^{2}} \Phi=0, \quad \Phi(-H)=\Phi(0)=0
$$
Here the eigen function $\Phi$ is the vertical structure function of internal waves. The estimation of Fr for the ADS area has shown that its maximum value hardly exceeds 0.4 , which

265 is insufficient for the lee wave mechanism to be realistic. It is interesting that the value ${ }_{266}$ of the phase speed for the first baroclinic mode in the area of M1 and M2 varies between ${ }_{267} 0.6 \mathrm{~m} \mathrm{~s}^{-1}$ and $0.9 \mathrm{~m} \mathrm{~s}^{-1}$, which is close to the phase speed of the wave packet calculated in ${ }_{268}$ previous subsection.

\subsection{T-beam generation mechanism}

The above analysis has shown that neither IBF theory, nor the lee-wave mechanism can explain the origin of the short-period internal waves propagating from the seamount centre. Another hypothesis to be tested is the "local" generation of internal waves due ${ }_{272}$ to the interaction of tidal beams with the seasonal pycnocline (hereafter, the T-beam analysis of Figure 3 where two tidal beam systems generated over ADS are clearly seen.

${ }_{275}$ In space these beams follow the characteristic lines (3) of the wave equation (4). Figure 9 a 276 shows two families of characteristic lines (lines $\mathrm{AD}$ and $\mathrm{BC}$ ) for the transect along $11.1^{\circ} \mathrm{W}$ 277 latitude that crosses the ADS centre. The characteristic lines touch the bottom at points ${ }_{278} \mathrm{~A}$ and $\mathrm{B}$ where their inclination coincides with the bottom steepness and where the tidal 
${ }_{279}$ beams are generated (see also Figure $3 \mathrm{~d}$ ). As discussed above, the tidal beams propagating 
${ }_{302}$ the seamount summit marked by letters $\mathrm{C}$ and $\mathrm{D}$. The latter coincide with the positions ${ }_{303}$ of $\mathrm{C}$ and $\mathrm{D}$ shown in Figures $9 \mathrm{a}$ and $9 \mathrm{~b}$.

$$
H(x, y)=1500-3000 \exp \left\{-\left[\left(x-x_{s}\right)^{2}+\left(y-y_{s}\right)^{2}\right] / 2500\right\}
$$

where $x_{s}$ and $y_{s}$ are the coordinates of its centre. The seamount's height, $H(x, z)$, was cut off at $700 \mathrm{~m}$ depth (minimum depth over ADS), and the sharp edges were smoothed by moving average across the topography from the seamount centre to its periphery using ten neighbouring grid points (Figure 11). The tidal parameters in these experiments were $A=B=100 \mathrm{~m}^{2} \mathrm{~s}^{-1}$, and $\phi=\pi / 2$ which turn the tidal ellipse (1) into a perfect circle. 
The upper panel of Figure 11 shows the sea surface displacements produced by internal waves over this symmetrical table seamount after 57 hours of model time. Analysis of the wave fronts' structure and their spatial evolution reveals that the strongest waves are generated within the red dotted circle, i.e. in a region above the flat bottom from which they propagate radially decreasing in amplitude as spiral-type waves. Thus Figure 11 confirms that the only possible explanation for these waves generation is the T-beam mechanism.

Maximum isotherm displacements in the epicentre of the generation area reach $20 \mathrm{~m}$ (see also Figure 6b), which is several times smaller than the internal tidal oscillations in the tidal beams $(\sim 100 \mathrm{~m})$. Parameters of the short-scale internal waves generated by tidal beams over idealized seamount or in the centre of ADS (these waves are visible in Figures $6,8,9,11$ ) can be sensitive to the level of the background mixing and the model resolution. Analysis of the sensitivity of the model output to the coefficient of the horizontal diffusion and grid step is presented in Appendix B.

\subsection{Implication for water mixing}

It is expected that tidally generated internal waves can modify the background stratification by inducing mixing. Zones with strong mixing can be identified using the Richardson number Ri. According to Miles [1961] and Howard [1961], some level of mixing (turbulence) is expected in regions where the Richardson number Ri drops below $1 / 4$ at least ${ }^{42}$ for a short period of time. Abarbanel et al. [1984] showed later that flows can be unstable even with $\mathrm{Ri}>1 / 4$, so for the qualitative analysis below we will take $\mathrm{Ri}=1$ as a threshold for possible mixing events. 
Figure $12 \mathrm{a}$ shows the area of the minimal Richardson numbers over one tidal cycle along the transect a-a, Figure 1, where Ri drops below 1. This pattern is overlaid with the amplitudes of horizontal velocities $\sqrt{u^{2}+v^{2}}$ to depict the positions of the tidal beams. The $0.2 \mathrm{~m} \mathrm{~s}^{-1}$ isoline is shown by a solid black line. The smallest values of the Richardson number are seen in the place where two tidal beams intersect between $50 \mathrm{~m}$ and $400 \mathrm{~m}$ depths just in the centre over the seamount summit. According to Figure $2 \mathrm{~b}$, the buoyancy frequency here drops to $0.0013 \mathrm{~s}^{-1}$, so strong vertical velocity shears associated with tidal beams can reduce the Richardson number in this layer below the critical level.

An obvious indicator for mixing processes can be the difference $\Delta T$ between the initial background temperature $T_{0}$ and the temperature $\langle T\rangle$ modified by the wave mixing

$$
\Delta T=<T>-T_{0}
$$

Here $\langle T\rangle$ is the temperature field averaged over one tidal period. Figure $12 \mathrm{~b}$ presents the temperature difference $\Delta T$ produced by internal wave mixing along section a-a (Figure 1) over five tidal periods. It shows a considerable drop of the temperature (up to $0.3^{\circ}$ ) in the surface layer and a similar temperature rise just below this layer. This temperature evolution can be treated in terms of internal wave activity that intensifies vertical mixing in the seasonal pycnocline. As it was shown in Figure 10 a, the areas of enhanced internal wave mixing are not evenly distributed in space. The temperature change $\Delta T$ at the depth of $30 \mathrm{~m}$ occupies a larger area to the south-south-west of the ADS summit than anywhere else, Figure $12 \mathrm{c}$. This happens because of the strongest T-beam generation of internal waves in this area.

As observational evidence of the intensification of local water mixing over the top of ADS due to internal waves, the temperature profile recorded at CTD station 43, which 
${ }_{368}$ was inside a simulated region of cooling shown in Figure $12 \mathrm{c}$, reveals substantially lower temperature in the surface layer in comparison with those measured at CTD stations 41

${ }_{371}$ Giovanni Web Portal https://giovanni.gsfc.nasa.gov/giovanni/) of the sea surface tem${ }_{372}$ perature (SST) collected by the MODIS-Aqua satellite. The SST anomalies calculated ${ }_{373}$ as a deviation from a long-term (years 2003-2016) mean May-August SST are shown in 374 Figure 13. Large-scale zonal and meridional gradients have been subtracted from the SST 375 field using a two-dimensional third-order polynomial. A very large area with SST more ${ }_{376}$ than $0.1^{\circ} \mathrm{C}$ lower than the surrounding area is located just over ADS (Figure 13). This 377 feature resulting from enhanced vertical mixing can be treated in terms of the mechanism 378 of baroclinic tidal energy focussing discussed above.

\section{Residual tidal currents}

In addition to internal waves, residual currents are also generated by periodical tidal ${ }_{380}$ flow over variable topography. These currents can be quite strong exceeding $10 \mathrm{~cm} \mathrm{~s}^{-1}$ over 381 the Malin Sea slope/shelf [Stashchuk et al., 2017] or even more than $20 \mathrm{~cm} \mathrm{~s}^{-1}$, around the 382 area of Georges Bank [Loder, 1980].

${ }_{383}$ As distinct from shelf/slope areas where residual tidal currents normally take the form ${ }_{384}$ of along-slope flows [Huthnance, 1973] in three dimensions a periodically alternating tidal 385 flow interacting with a seamount generates a dipole of eddies and density anomalies rotat386 ing around the seamount [Haidvogel et al., 1993]. Note, however, that the tidal forcing in 387 the latter model was activated by a periodic barotropic discharge prescribed at one open ${ }_{388}$ boundary, whereas three other boundaries were taken as rigid walls. Such an approach звя results in the generation of standing waves instead of progressive waves and inertial os- 
390 cillations that do not reproduce real tidal flow over an isolated bank located in the open 391 sea. 
${ }_{413}$ structure of these model-predicted residual currents and their intensity are consistent with ${ }_{414}$ that recorded in-situ in mid-June 2009, [Sherwin et al., 2015]. Figure 14 shows that in ${ }_{415}$ the vertical direction the eddies extend from the surface to the bottom of the seamount ${ }_{416}$ having mostly constant velocity over the whole water column.

\subsection{Biological implications}

${ }_{417}$ Recent investigations by Henry et al. [2014] around Hebrides Terrace Seamount (North${ }_{418}$ East Atlantic ocean) have suggested that internal tides may enhance biological diversity

${ }_{434}$ in the laboratory.) 
446

A large number of experiments revealed several realistic scenarios of larvae dispersion. In general, the vast majority of particles moved around the bank transported by residual currents. They were deposited at different places giving birth to new local colonies of corals. Some particles escape from the bank and can be considered as a potential source for wider spreading in the marine environment. We illustrate here the most interesting trajectories of four particular experiments. The particles started their journey from four different positions where the ROV conducted its dives, Figure 1. Specifically, one particle started from the seamount summit (dive 272), and three others from the northern flank of ADS (dives 270, 271, and 296). Geographically their positions were very close to each other, although due to steep topography they started at very different depths, i.e. at Figure 15 a shows a plan view of the trajectories of the particles overlapped with the field of residual currents, and Figure $15 \mathrm{~b}$ represents the particle tracks in three dimensions. The complex structure of the residual currents around the bank has a clear effect on the particle dispersion. Particles marked by green and red (dives 296 and 270) moved clockwise and the particle coloured with blue (dive 271) propagated counter-clockwise. 1 Two particles in the north-east part left the seamount with strong outgoing currents. Another couple of particles do the same but at the south-western part of seamount. 43 Figure $15 \mathrm{~b}$ shows that trajectories of particles are quite complicated in three dimensions. ${ }^{54}$ They show the potential for larvae to change depth with ascending or descending currents generated around the seamount, which is quite important for their wider dispersion. 


\section{Conclusions}

472 process was given by Gerkema [2001]. The novel element of our study is that local T-beam

${ }_{473}$ generation is confirmed for a circular bank, specifically, over its centre where tidal beams

${ }_{474}$ intersect as a result of energy focusing. Taking into account that there are more than 
${ }_{478}$ The most interesting ecological outcome from this study concerns the pattern of the ${ }_{479}$ residual currents generated by tides interacting with an isolated seamount. This effect ${ }_{480}$ resulting from tidal rectification along 2-dimensional topography was explained by Huth${ }_{481}$ nance [1973] and Loder [1980]. In application to a 3D object like ADS this theory predicts ${ }_{482}$ generation of two dipoles of cyclonic and anti-cyclonic eddies located at the seamount's ${ }_{483}$ periphery, Stashchuk et al. [2017]. They can be an important factor in coral larvae disper${ }_{484}$ sion including their escape from the seamount and travel to other banks of the World's ${ }_{485}$ Ocean. 


\section{Appendix A: Residual tidal currents over an idealized Gaussian bank}

where $H(x, y)$ is the bottom profile and $x_{s}$ and $y_{s}$ are the coordinates of the seamount's centre. The tidal currents were set in the model according to (1) with $A=B=100 \mathrm{~m}^{2} \mathrm{~s}^{-1}$ (close to the discharge considered in the main series of runs). The configuration of tidal ellipses was set by the phase $\phi: \phi=0$ corresponds to a periodical reversal flow, whereas $\phi=\pi / 2$ defines a perfect circle. The tidal phase $\phi$ between 0 and $\pi / 2$ sets a tidal ellipse. 


\section{A1. Barotropic response}

In homogeneous fluids the tidally induced along-slope residual current $v^{c}$ over a meridionally oriented continental slope can be calculated using the following formula [Stashchuk et al., 2017]:

$$
v^{c}=\frac{A B \cos (\phi)}{2 C_{D} \sqrt{A^{2}+B^{2}}} \frac{1}{H(x)} \frac{\partial H(x)}{\partial x} .
$$

Here $H(x)$ is the bottom profile across the slope, and $C_{d}=0.013$. Applying this formulae to a singular circular object like the Gaussian seamount defined by (A1), one should take into account the orientation of the bottom gradient as well. An accurate correction of (A2) that takes into account the bottom orientation and the coordinate transforms was provided in Stashchuk et al. [2017]. Considering positions at the periphery of the bank and moving around it along isobaths this formulae predicts that the residual along-bank slope current should change its sign four times depending on the location of the quadrant where it is applied. As a result of this spatial variability, four eddies are expected to be generated over the bank according to this analysis. This is exactly what the MITgcm predicts for the Gaussian-type bank (A1).

Figure A.1 shows patterns of residual currents (middle row) and the vorticity $u_{y}-v_{x}$ (bottom row) at a depth of $600 \mathrm{~m}$ for three different tidal configurations. A reversal tidal flow mostly typical for weak rotation is presented in the left column $(\phi=0)$, the midlatitude conditions are reproduced in the middle column $(\phi=\pi / 4)$, and the case of strong rotation is shown in the right column $(\phi=\pi / 2)$. It is clear from Figure A.1 that the MITgcm predicts the generation of four eddies over the seamount top: two cyclonic eddies arranged along the major tidal semi-axis, and two anti-cyclonic eddies whose positions are 
${ }_{528}$ consistent with the direction of the minor semi-axis. The vorticity patterns also clearly 
${ }_{550}$ its the periphery as in the barotropic case. And finally, the positive upward water fluxes are located on either sides of the downwelling area. Overall, the baroclinic residual tidal $552 \quad$ signal looks much stronger.

\section{Appendix B: Sensitivity to background mixing and grid resolution}


$K_{e}=K_{h}+\frac{1}{2 \omega^{2}}\left(\frac{d u}{d z}\right)^{2} \kappa$.

${ }_{571}$ Here $d u / d z$ is the velocity shear; $\omega$ is the frequency of the oscillating tidal current; $K_{h}$ ${ }_{572}$ and $\kappa$ are the coefficients of the background horizontal and vertical diffusivity, respec${ }_{573}$ tively (for the details of this theory we refer the reader to the original paper). The

Acknowledgments. This work was supported by the UK NERC grant NE/K011855/1. The authors would like to thank the captain, the crew and the ROV ISIS team working during the JC136 cruise. The used data are available at https://figshare.com/articles/Untitled_Item/5472451. More details on the 136-th Cruise of the RRS "James Cook" can be found at https://deeplinksproject.wordpress.com/ and https://www.bodc.ac.uk/resources/inventories/cruise_inventory/report/16050/. We 
are very grateful to the Chief Editor, Associate Editor and two Reviewers for their sup-

portive comments, which helped us to focus the manuscript.

\section{References}


Henry, L.-A., J. Vad, H. S. Findlay, J. Murillo, R. Miligan, and J. M. Roberts (2014), Environmental variability and biodiversity of megabentos on the Hebrides Terrace Seamount (Northeast Atlantic), Sci. Rep., 4, 5589, doi:10.1038/srep05589(2014).

Howard, L.N. (1961), A note on the paper of John W. Miles. J. Fluid Mech., 10, 509-512. Huthnance, J.M.(1973), Tidal current asymmetries over the Norfolk sandbanks. Estuar. Coastal Mar. Sci., 1, 89-99.

Larsson, A.J., J. Järnegren, S.M. Strömberg, M.P. Dahl, T. Lundälv, and S. Brooke (2014) Embryogenesis and larval biology of cold-water coral Lophelia pertusa, PLoS ONE, 9(7), e102222, doi:101371/journal.pone.0102222.

Lavelle, J.W., and C. Mohn (2010), Motion, commotion, and biophysical connections at deep ocean seamounts. Oceanography, 23(1), 91-103.

Loder, J.W. (1980), Topographic rectification of tidal currents on the sides of Georges Bank. J. Phys. Oceanogr., 10, 1399-1416.

Marshall, J., A. Adcroft, C. Hill, L. Perelman, and C. Heisey (1997), A finite-volume, incompressible Navier-Stokes model for studies of the ocean on the parallel computers, J. Geophys. Res., 102, 5733-5752.

Miles, J.W. (1961), On stability of heterogeneous shear flows. J. Fluid Mech., 10, 496-508. Morato, T., S. D. Hoyle, V. Allain, and S. J. Nical (2010), Seamounts are hotspots of pelagic biodiversity in the open ocean, PNAS, 107(21), 9707-9711, doi:10.1073/pnas.0910290107.

Rogers, A. (1994), The biology of Seamounts, Advances in Marine Biology, 30, 305-351. Pacanowski, R.C., and S. G. H. Philander (1981), Parametrisation of vertical mixing in numerical models of Tropical Oceans, J. Phys. Oceanogr., 11, 1443-1451. 
Pingree, R.D., and L. Maddock (1980), Tidally induced residual flows around an island due to both frictional and rotational effects, J. Geophys. J. R. Astr. Soc., 63, 533-546.

Pingree, R.D., and G.T. Mardell (1981), Slope turbulence, internal waves and phytoplankton growth at the Celtic Sea shelf-break, Phil. Trans. R. Soc. Lond. A, 302, 663-682.

Pingree, R.D., and G.T. Mardell (1985) Solitary internal waves in the Celtic Sea. Prog. Oceanogr., 14, 431-441.

Sherwin, T.J., D. Aleynik, E. Dumont, and M.E. Inall (2015), Deep drivers of mesoscale circulation in the central Rockall Trough. Ocean Sci., 11, 349-359.

Stashchuk, N., and K. Hutter (2001), Modelling of water exchange through the Strait of the Dardanelles. Cont. Shelf. Res., 21, 1361-1382.

Stashchuk, N., Vlasenko, V., P. Hosegood, and A. Nimmo-Smith (2017), Tidally induced residual current over the Malin Sea continental slope. Cont. Shelf. Res., 139, 21-34.

Stashchuk, N., Vlasenko, V., M.E. Inall, and D. Aleyinik (2014), Horizontal dispersion in shelf seas: High resolution modelling as an aid to sparse sampling. Progr. Oceanogr., $128,74-87$.

Visbeck, M. (2002), Deep velocity profiling using lowered acoustic Doppler current profilers: bottom track and inverse solutions. J. Atmos. and Ocean Tech., 19,794-807.

Vlasenko, V. (1994), Multimodal soliton of internal waves. Izvestiya Atmospheric and Oceanic Physics, 30(2), 161-169.

Vlasenko, V., and N. Stashchuk (2006), Amplification and suppression of internal waves by tides over variable bottom topography. J. of Phys. Oceanogr,, 36(10), 1959-1973.

Vlasenko, V., and N. Stashchuk (2015), Internal tides near the Celtic Sea shelf break: A new look at a well known problem. Deep Sea Res.I, 103, 24-36, 
${ }_{659}$ doi:10.1016/dsr.2015.05.003.

${ }_{660}$ Vlasenko, V., N. Stashchuk, M.R. Palmer, and M.E. Inall (2013), Generation of baroclinic

${ }_{661}$ tides over an isolated underwater bank. J. Geophys. Res., 118(9), 4395-4408.

${ }_{662}$ Vlasenko V., N. Stashchuk, and K. Hutter (2005), Baroclinic tides: theoretical modeling

${ }_{663}$ and observational evidence. Cambridge University Press. 365 pp.

${ }_{664}$ Vlasenko V., N. Stashchuk, M. E. Inall, and J. Hopkins (2014), Tidal energy conversion in ${ }_{665}$ a global hot spot: on the 3D dynamics of baroclinic tides at the Celtic Sea shelf break,

${ }_{666}$ J. Geophys. Res., 119(6), 3249-3265, doi:10.1002/2013JC009708.

${ }_{667}$ Vlasenko V., N. Stashchuk, M. E. Inall, M. Porter, and D. Aleynik (2016), Fo${ }_{668}$ cusing of baroclinic tidal energy in a canyon. J. Geophys. Res. Oceans, 121, ${ }_{669}$ doi:10.1002/2015JC011314.

${ }_{670}$ Wessel, P., D.T. Sandwell, and S.-S. Kim (2010), The global seamount census. Oceanog${ }_{671} \quad$ raphy, 23(1), 24-33.

${ }_{672}$ Young, W.R., P.B. Rhines, and C.J.R. Garrett (1982), Shear-flow dispersion, internal waves and horizontal mixing in the ocean. J. of Phys. Oceanogr., 12, 515-527. 


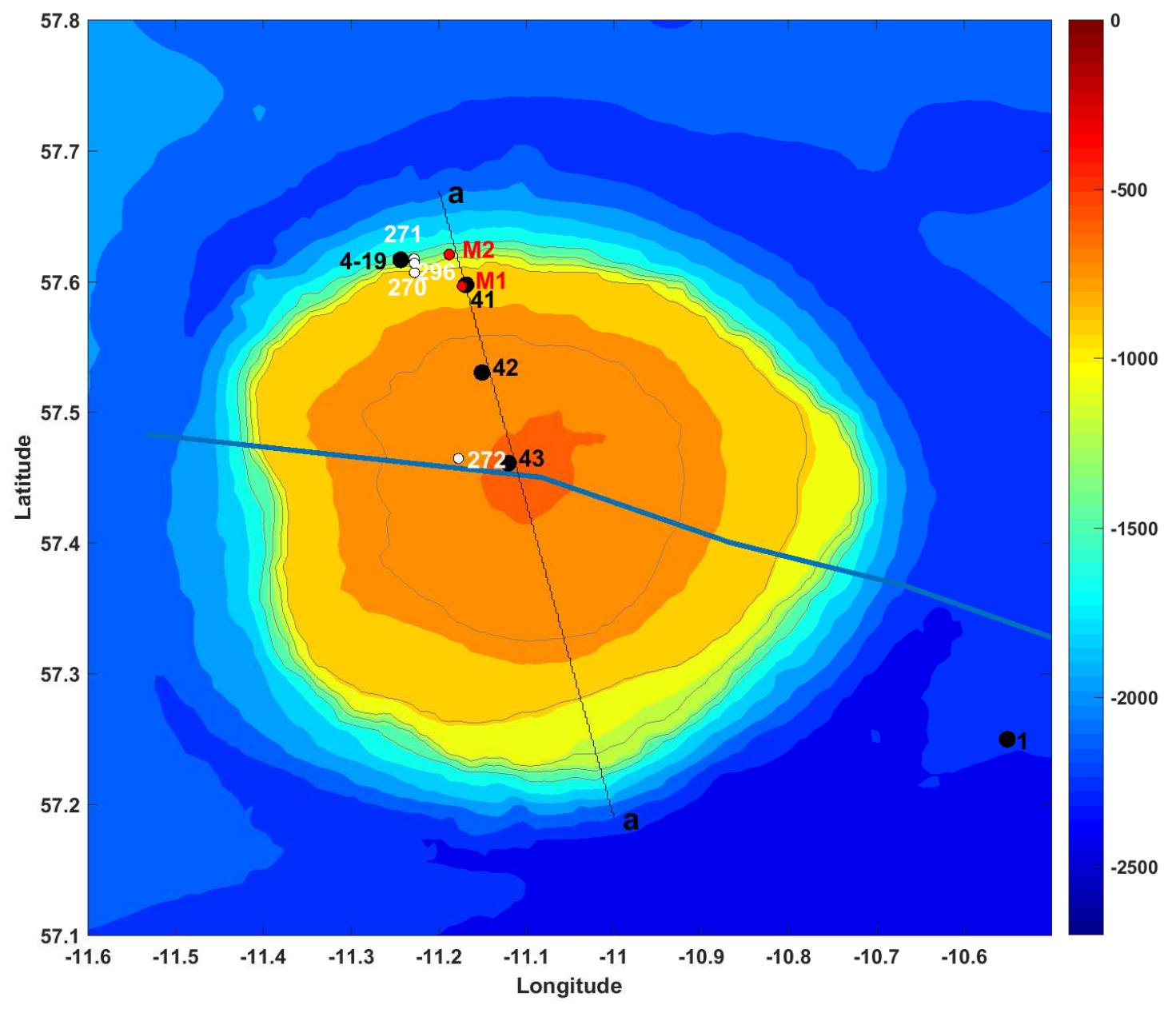

Figure 1. Topography of ADS with positions of CTD stations (black), moorings (red), and ROV dives (white dots). The Ellett Line along which regular CTD surveys have been conducted since 1975 is shown by the blue line (www.o-snap.org). The thin solid line (a-a) shows the transect used for the analysis of the model output. 

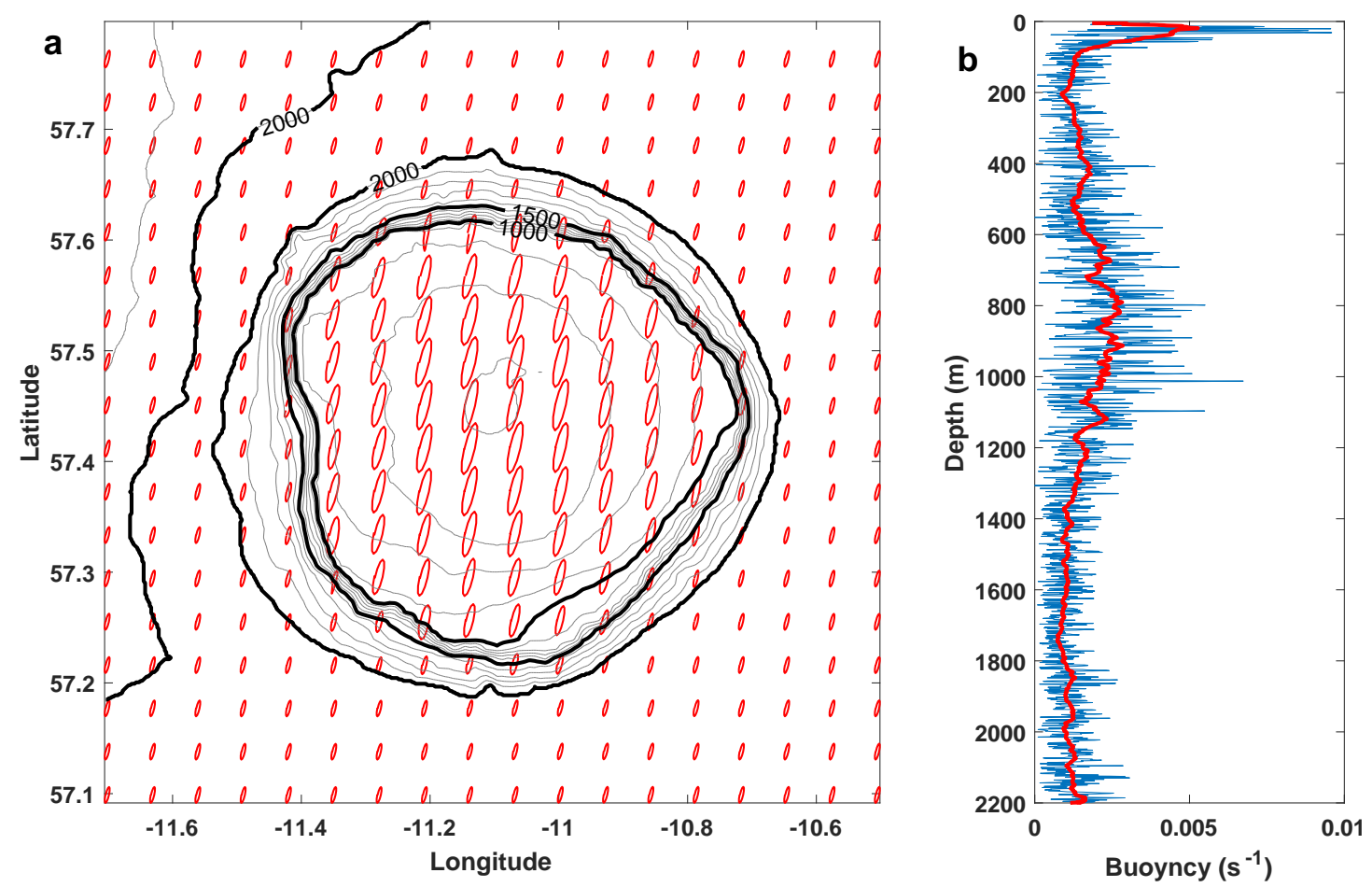

Figure 2. a) Tidal elipses in the area of ADS predicted by the TPXO8.1 inverse tidal model.

b) Instant (blue) and smoothed (red) buoyancy frequency profiles recorded at CTD station 1. 

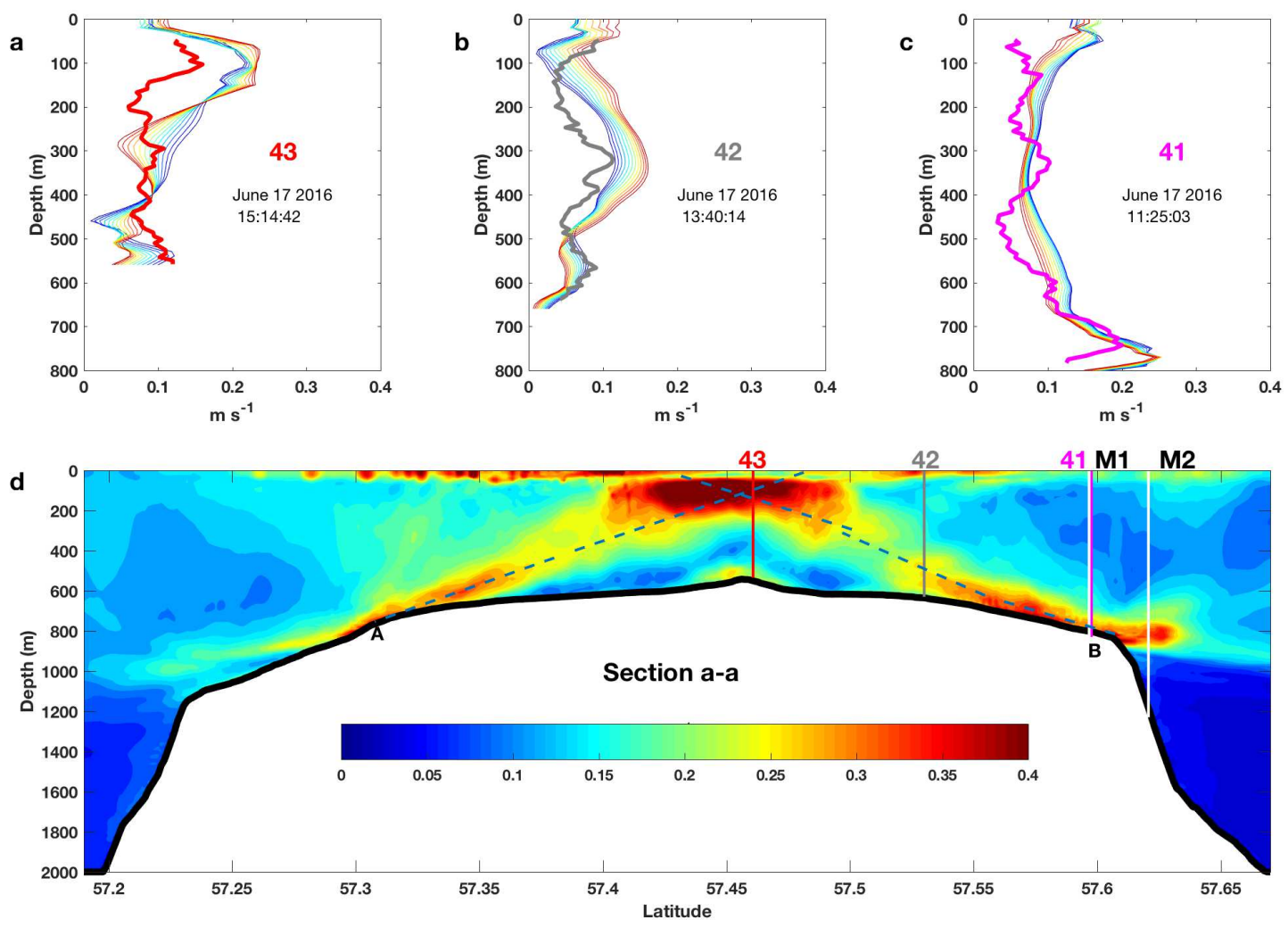

Figure 3. (a-c) Profiles of the horizontal velocity amplitude $\sqrt{u^{2}+v^{2}}$ at CTD stations 41-43. Thick lines represent the in-situ recorded profiles, thin coloured lines depict the model predicted curves with five minutes temporal interval starting from the time of real CTD sampling. (d) Model predicted amplitudes of horizontal velocities in the cross-section a-a, Figure 1. Positions of the CTD stations 41-43 and moorings M1 and M2 are shown by vertical lines. Dashed curves depict the positions of tidal beams. 

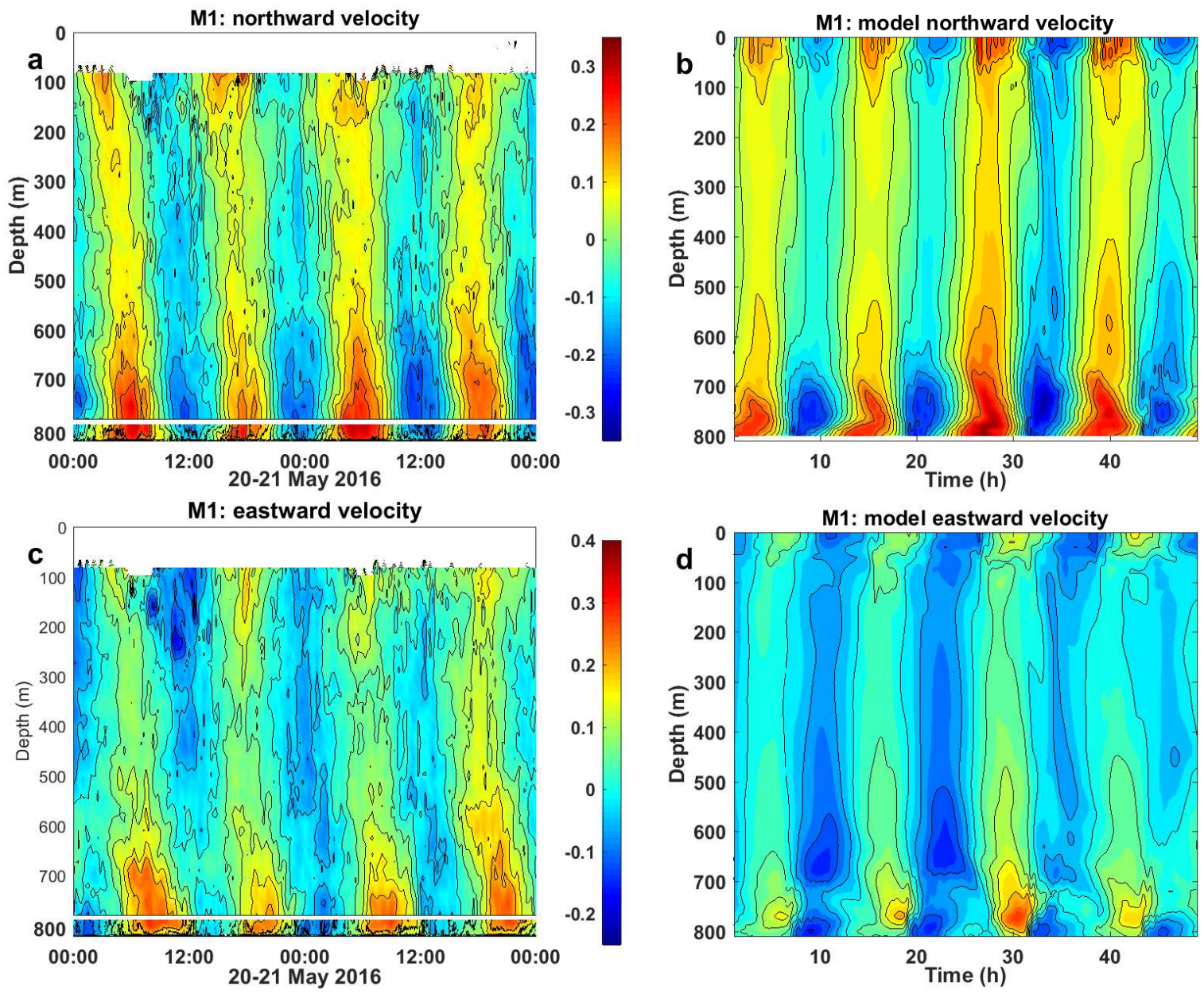

Figure 4. Two day time series of zonal $(\mathrm{a}, \mathrm{c})$ and meridional $(\mathrm{b}, \mathrm{d})$ velocities recorded at mooring M1 (left column) and predicted by the model (right column). 

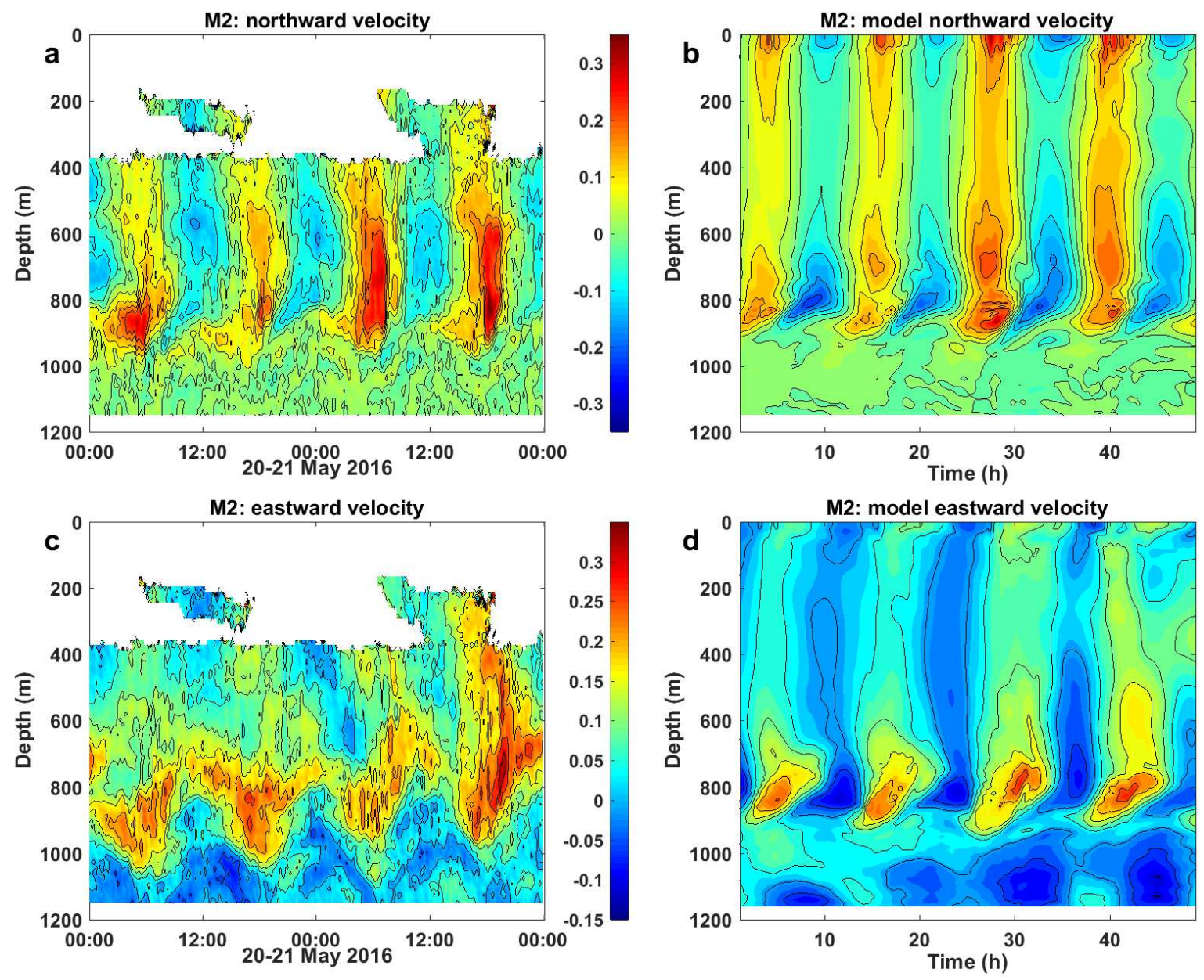

Figure 5. The same as in Figure 4 but for mooring M2. 



Figure 6. Vertical velocities recorded at moorings M1 and M2 (left) and reproduced by the model (right). The model predicted velocities are overlaid with the temperature field. Red dotted ellipses in panels $\mathrm{b}$ and $\mathrm{d}$ show the packets of short-scale internal waves. 

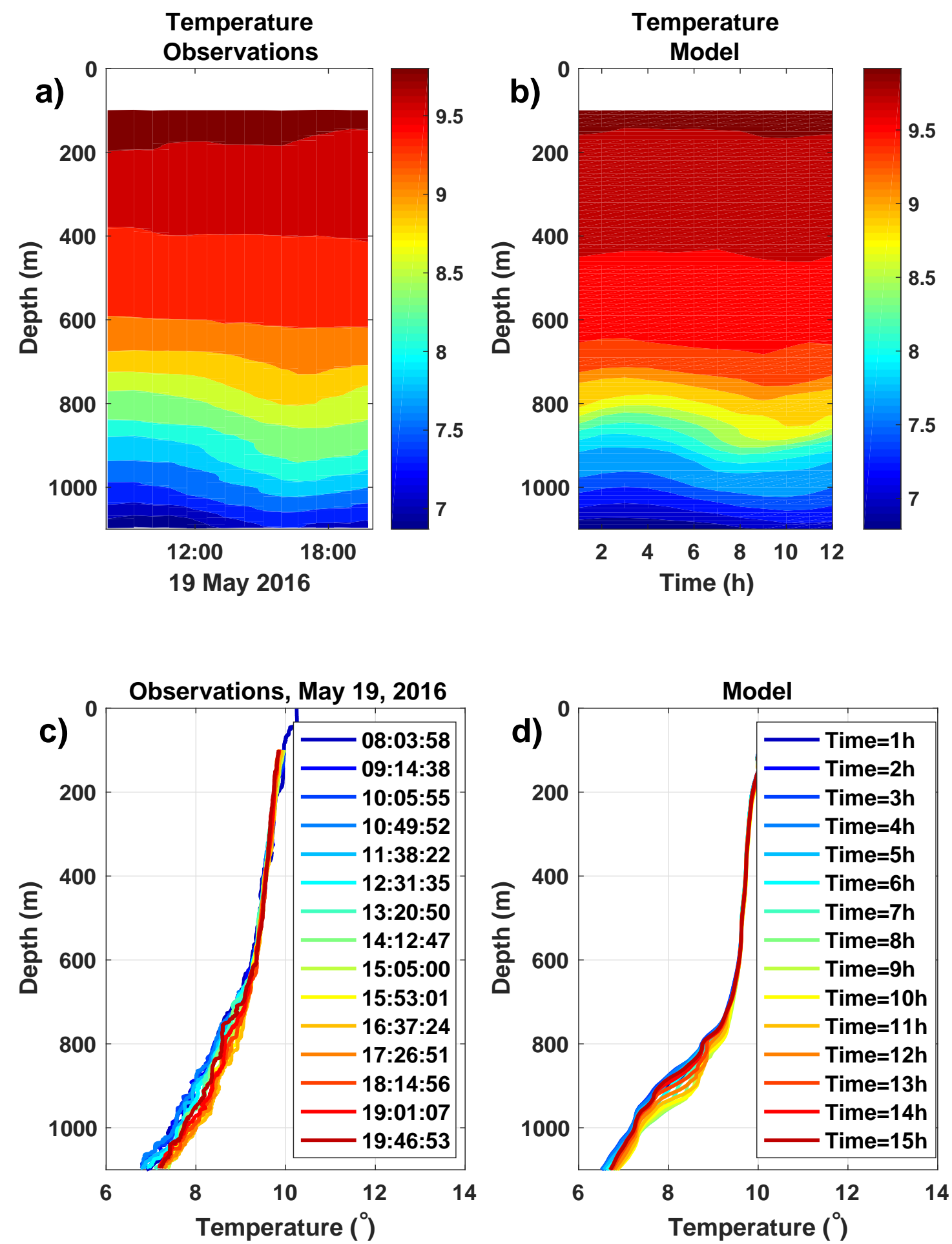

Figure 7. Observational (a) and model predicted (b) temperature time series recorded at the yo-yo CTD station on 19th May 2016. Temperature profiles for the yo-yo station position recorded in-situ (c) and predicted by the model (d).
D R A F T
January 17, 2018, 10:45am
D R A F T 

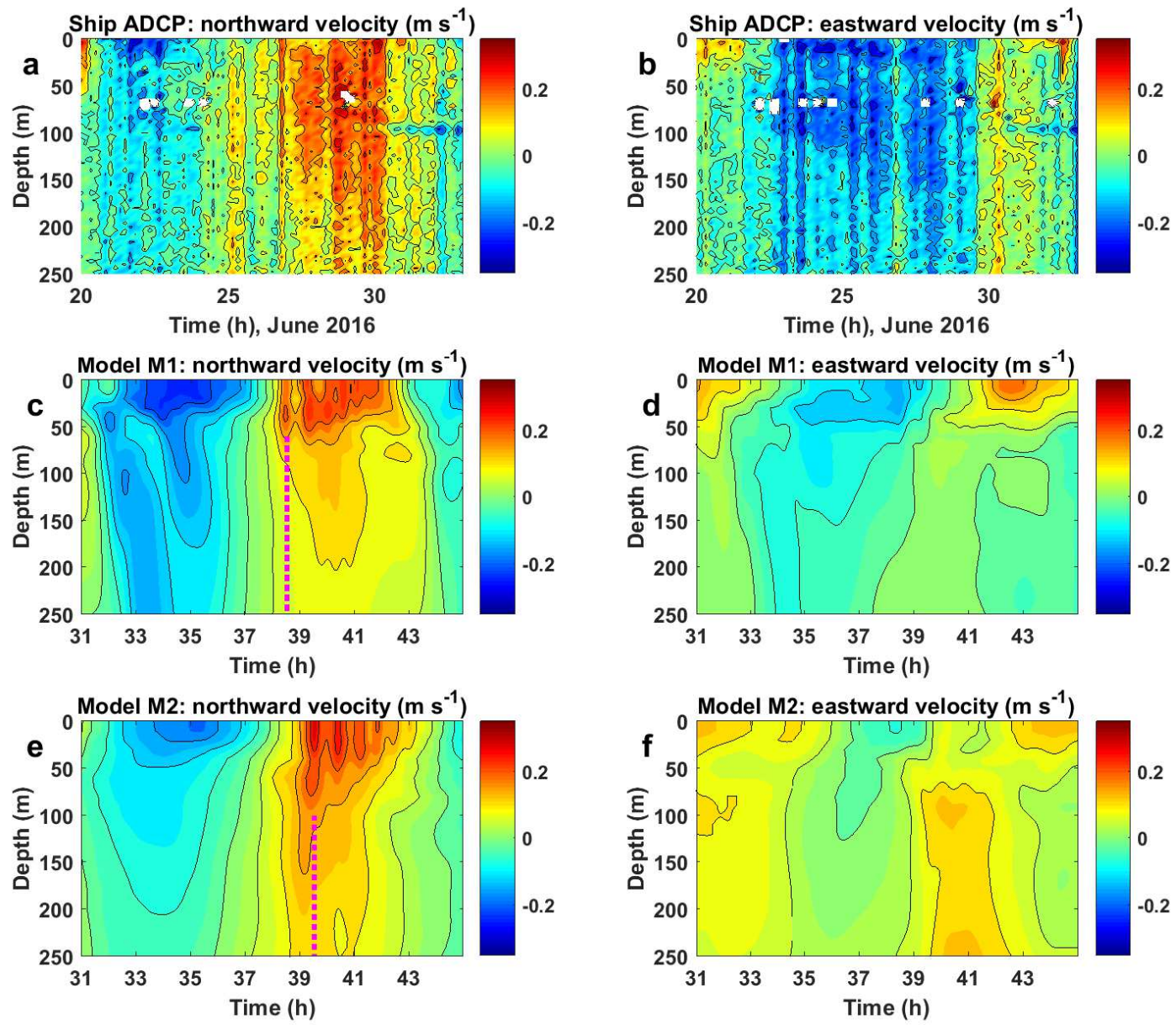

Figure 8. Meridional (left column) and zonal (right column) velocities recorded by the ship mounted ADCP during ROV dive 296 (panels a and b) and predicted by the model (panels c, d, e, and $\mathrm{f}$ ) at the positions of M1 and M2 moorings during the ROV dive. 

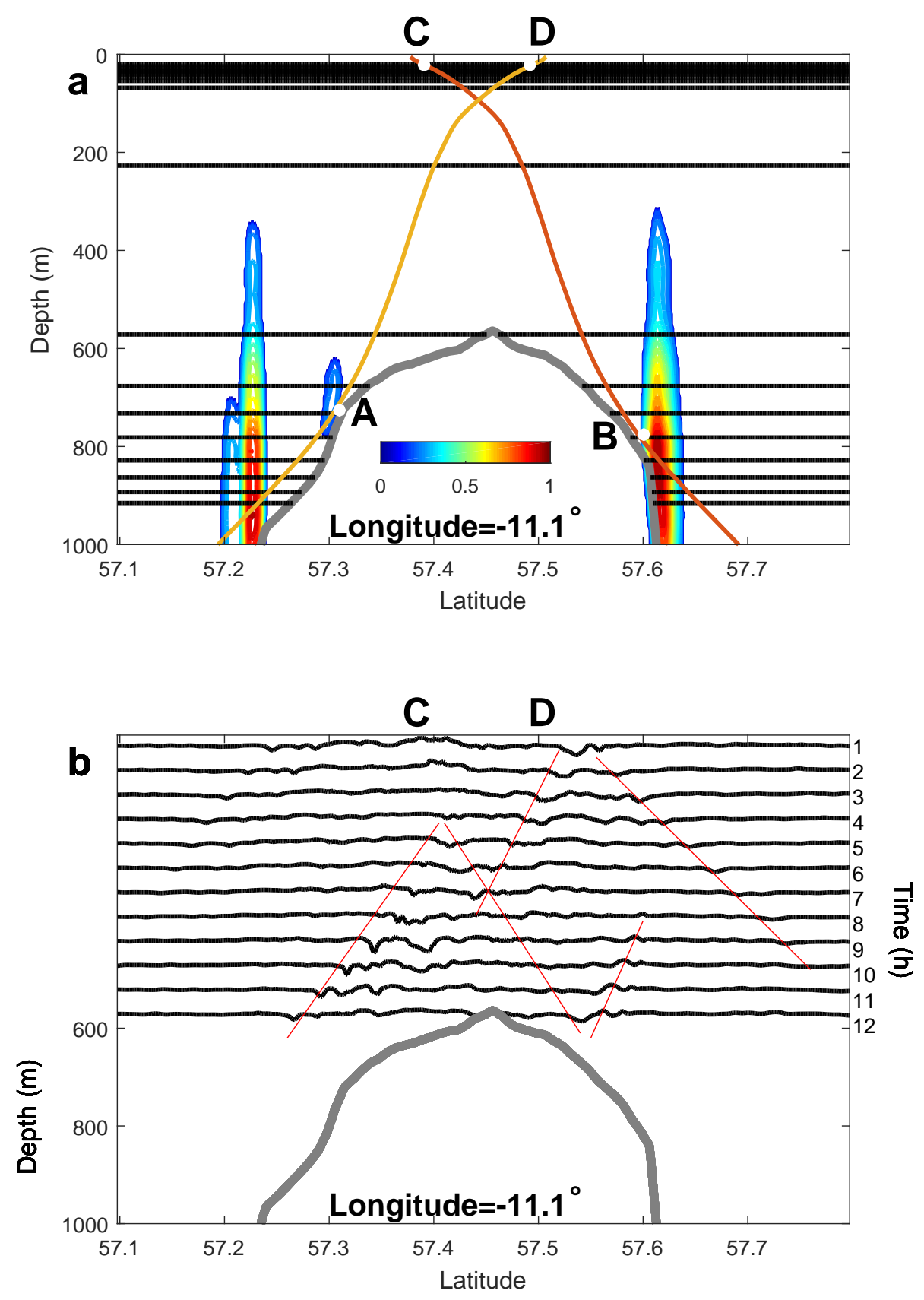

Figure 9. a) Meridional $11.1^{\circ} \mathrm{W}$ cross-section of undisturbed temperature field through the $\mathrm{ADC}$ summit. The interval between isotherms equals $0.25^{\circ} \mathrm{C}$. Contours $\mathrm{AD}$ and $\mathrm{BC}$ are characteristic lines (3). Vertically oriented coloured zones show positions of the maxima of normalized IBF (5). b) Hovmöller diagram showing evolution of isotherm $12^{\circ}$ along the longitude $11.1^{\circ} \mathrm{W}$. Time interval between contours equals 1 hour. The red lines depict the positions of wave packets. D R A F T January 17, 2018, 10:45am D R A F T 

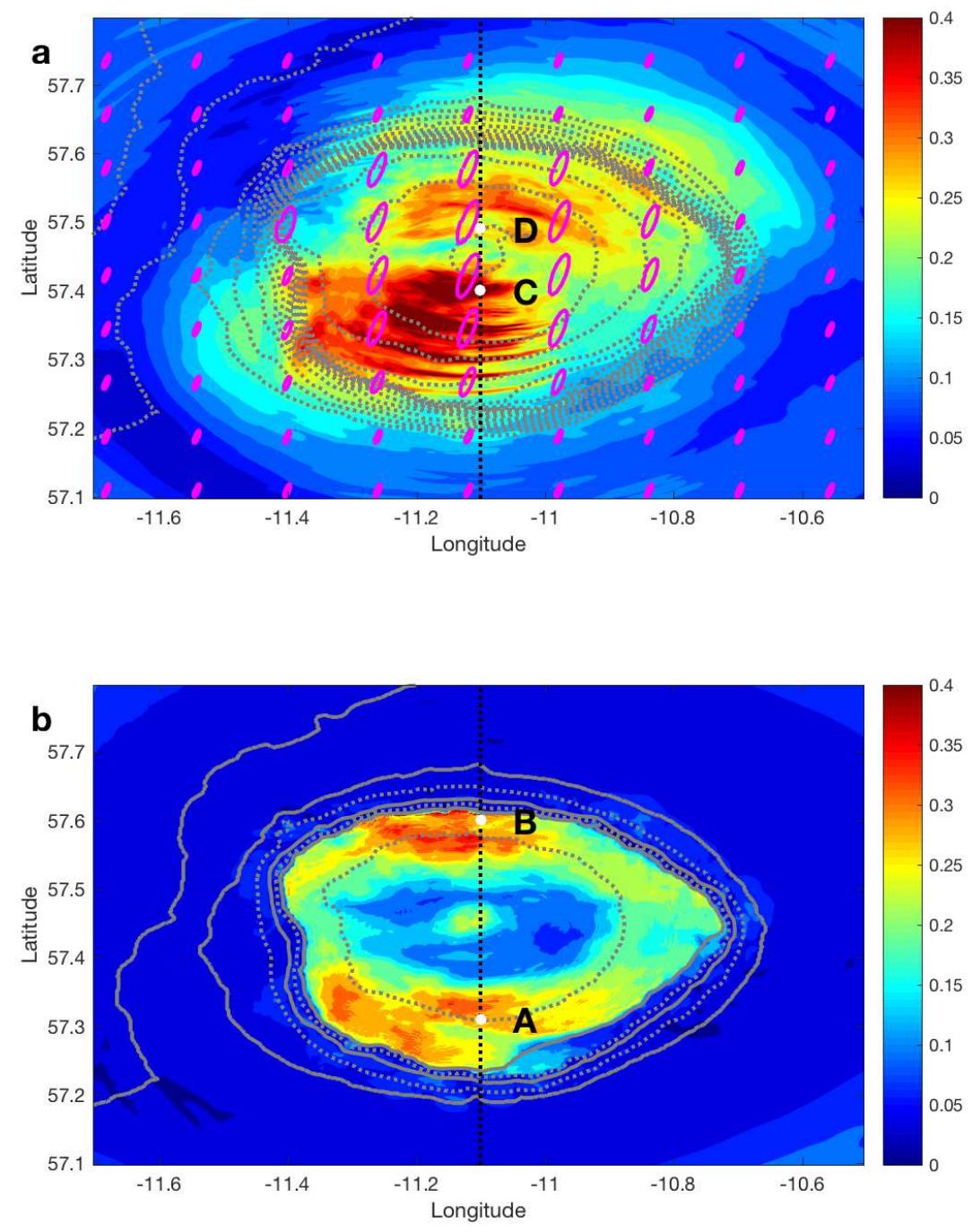

Figure 10. Amplitude of horizontal velocity $\sqrt{u^{2}+v^{2}}\left(\mathrm{~ms}^{-1}\right)$ at the free surface (a) and $10 \mathrm{~m}$ above the bottom (b). Position of the $11.1^{\circ} \mathrm{W}$ section is shown by the dashed line. Points A, B, C and D correspond to those shown in Fig. 9. 

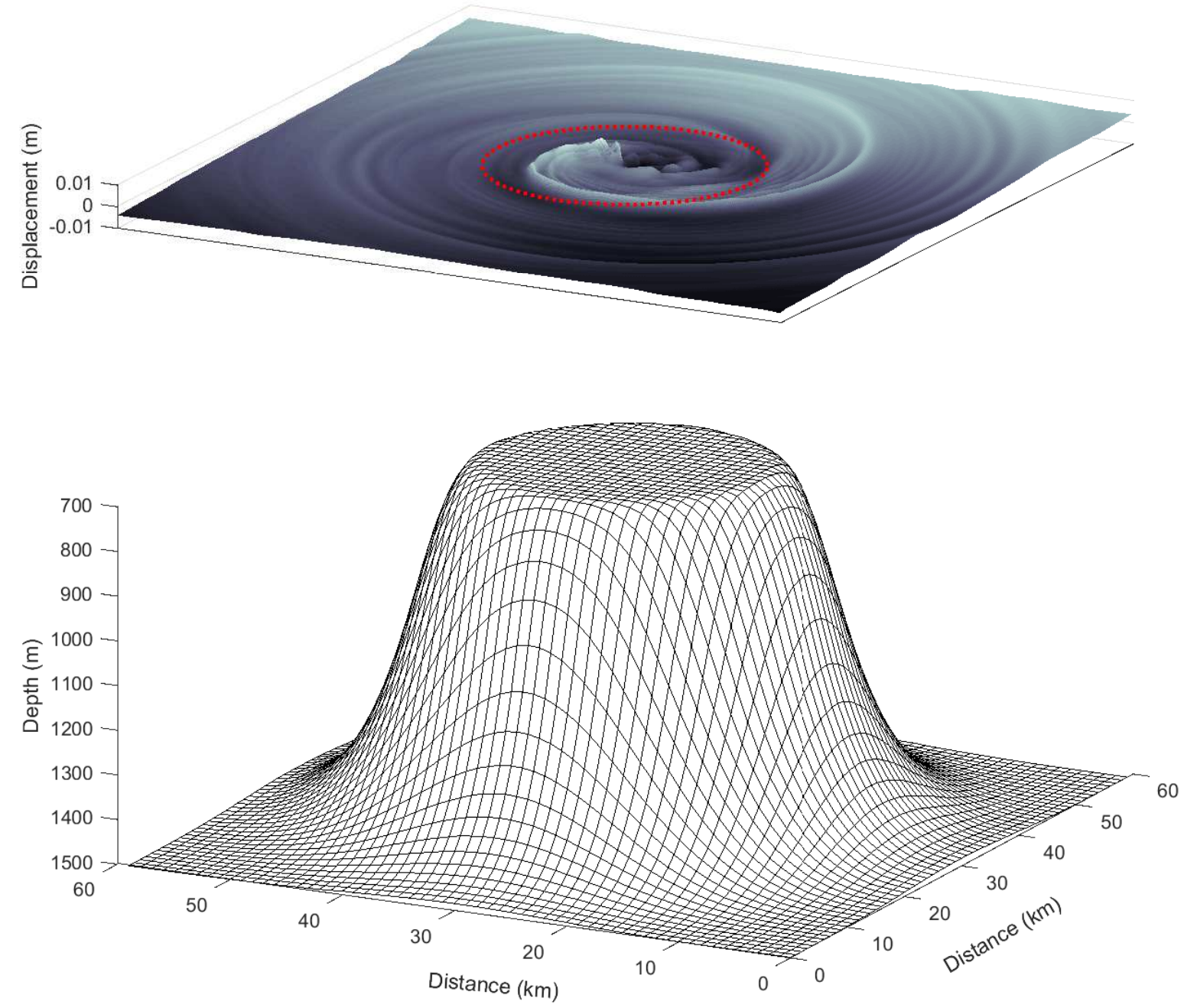

Figure 11. Sea surface displacements produced by internal waves over an isolated symmetrical table seamount. Surface elevations and depressions are shown by white and black colors, respectively. Red dotted line represents a central (flat) part of the bank depicted in the bottom panel. 

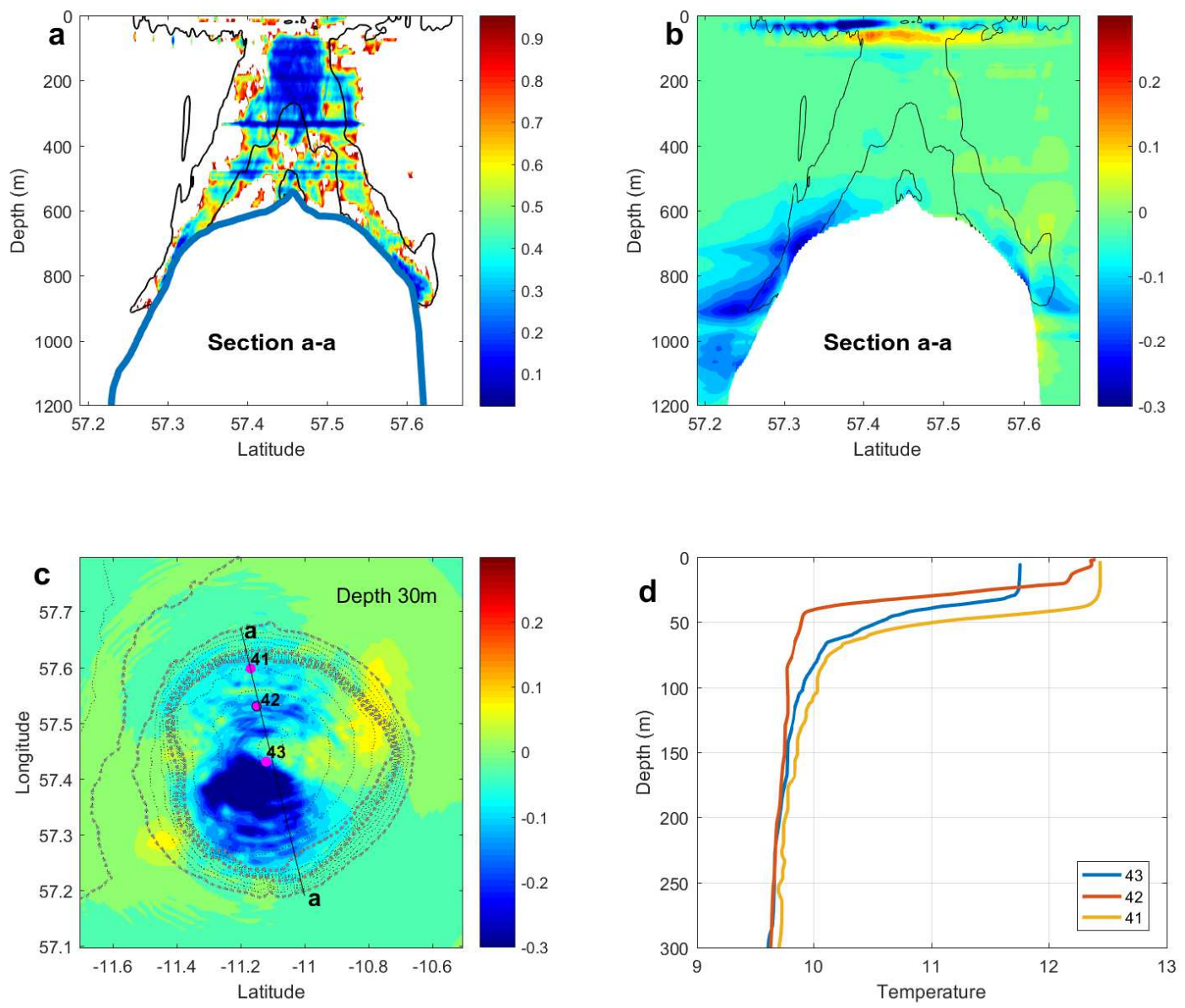

Figure 12. a) Model predicted minimum value of the Richardson number over a tidal period at the transect a-a shown in panels c). b) Difference between initial temperature and that modified by internal wave mixing. The solid black lines in panel a) and b) show velocity magnitude 0.2 $\mathrm{ms}^{-1}$. c) Temperature field modifications induced by internal waves in the surface layer. d) Vertical temperature profile recorded at CTD stations 41-43. 


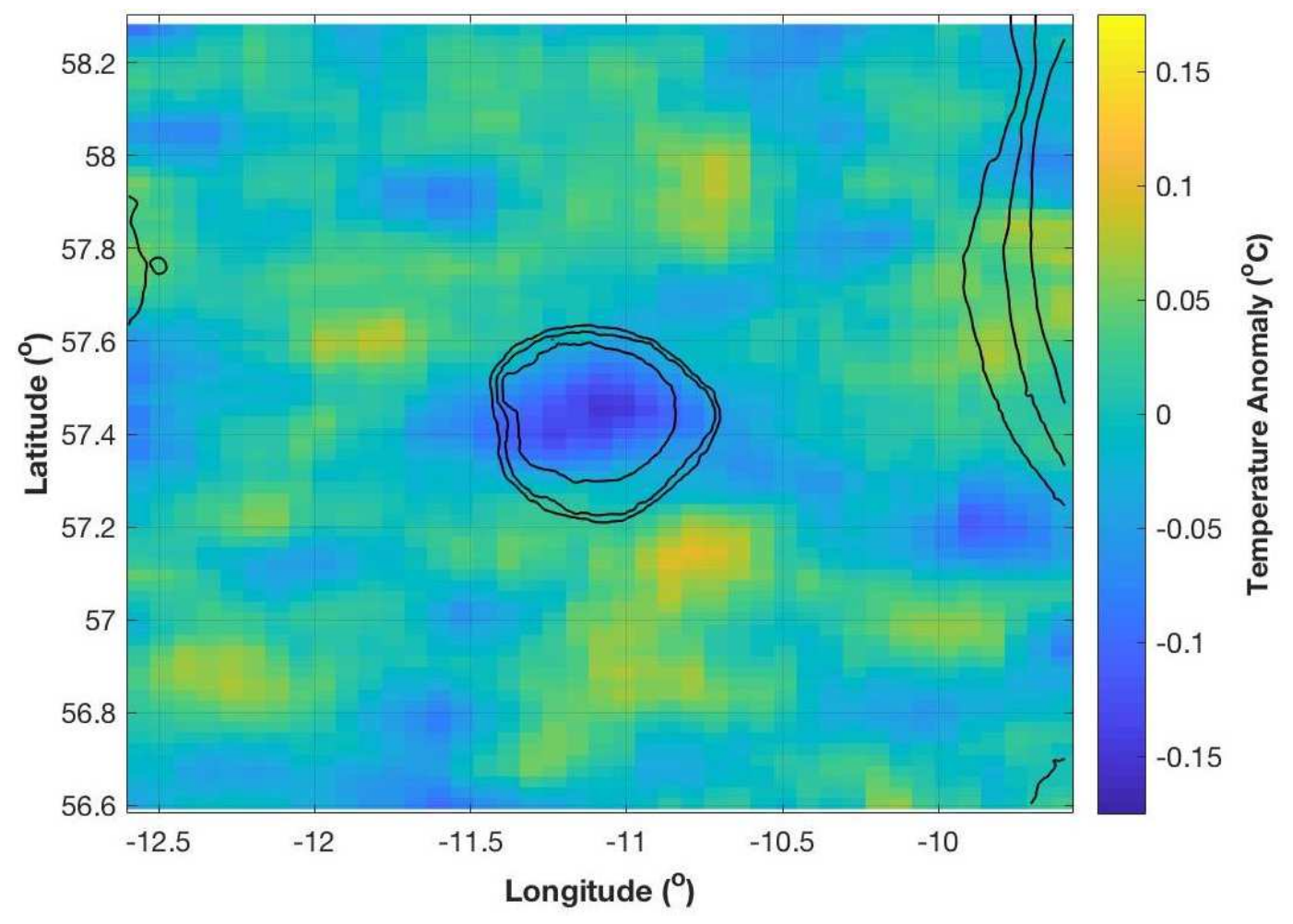

Figure 13. Deviation of the sea surface temperature (SST) from an average SST recorded by MODIS-Aqua satellite in May - August 2003-2016. Large-scale zonal and meridional gradients have been subtracted using a two-dimensional third-order polynomial. 
a)

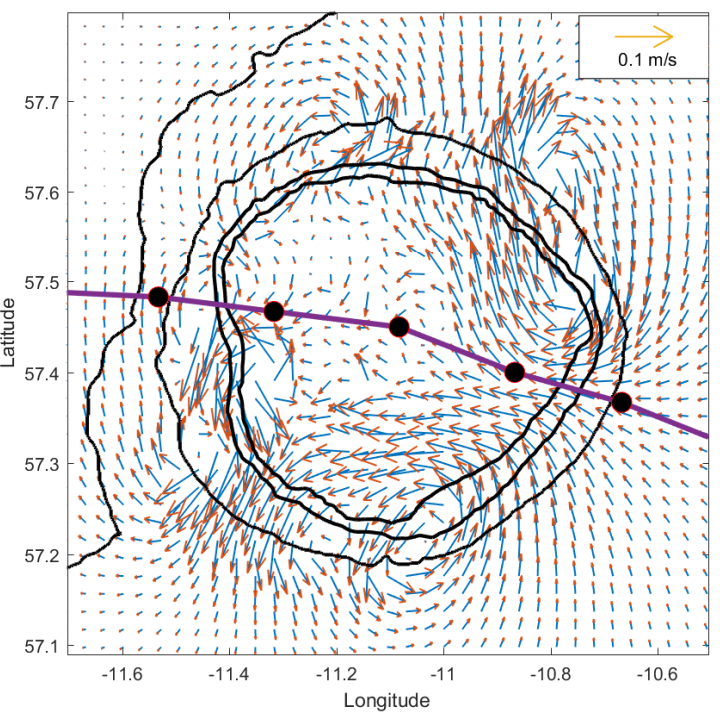



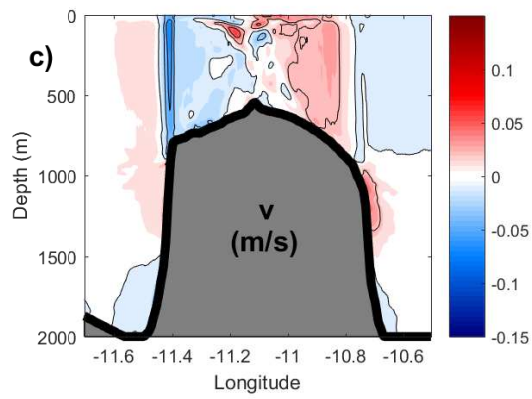

Figure 14. a) Model predicted residual currents generated over ADS at 500-m depth. The velocity fields were averaged over five tidal cycles. The black line with dots shows the Ellet Line. Residual zonal (b) and meridional (c) velocities along the Ellet Line predicted by the model. 

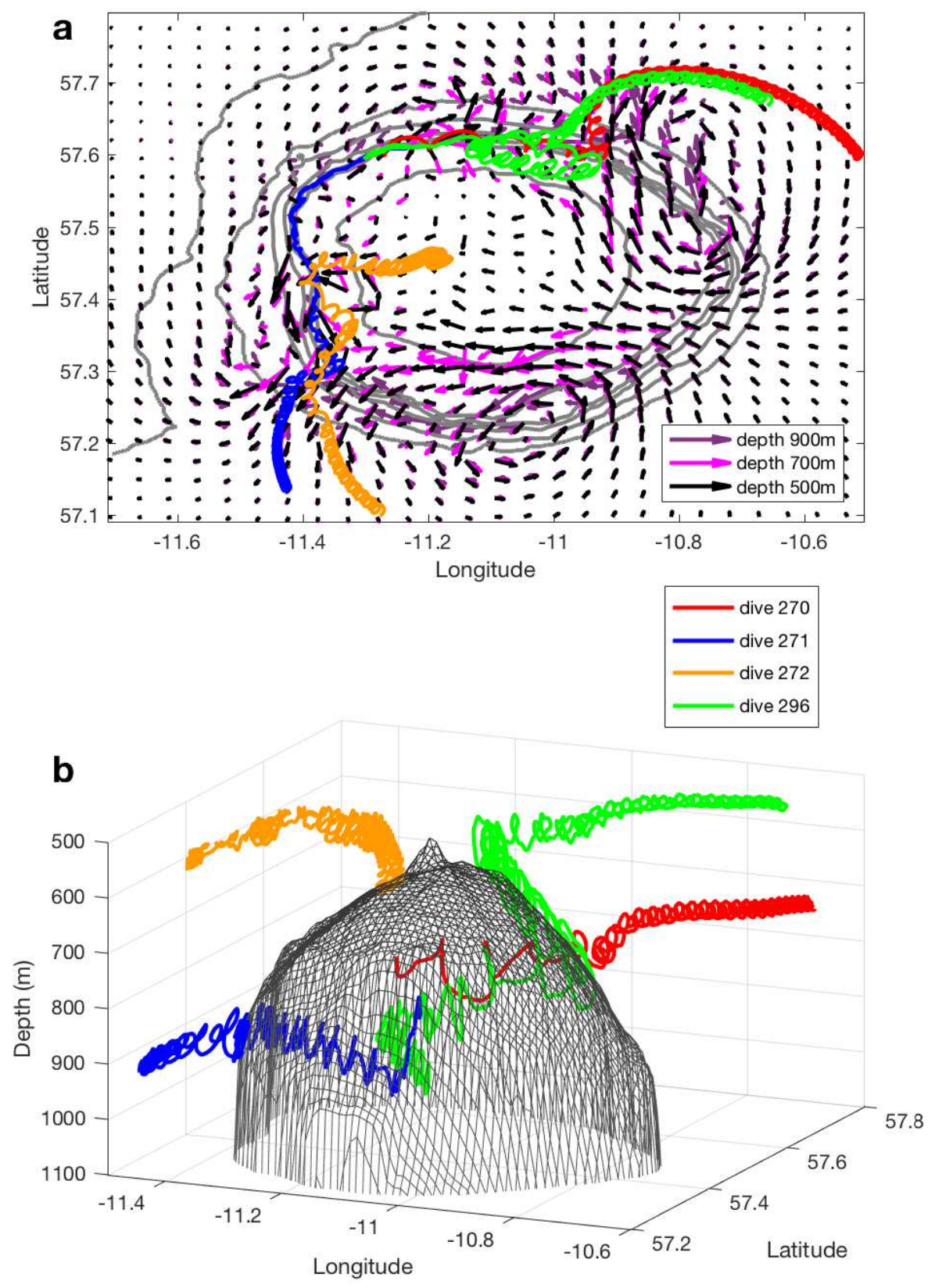

Figure 15. a) Plan view of the trajectories of the particles overlapped with the field of residual currents. b) Three dimensional projection of the particle trajectories. 

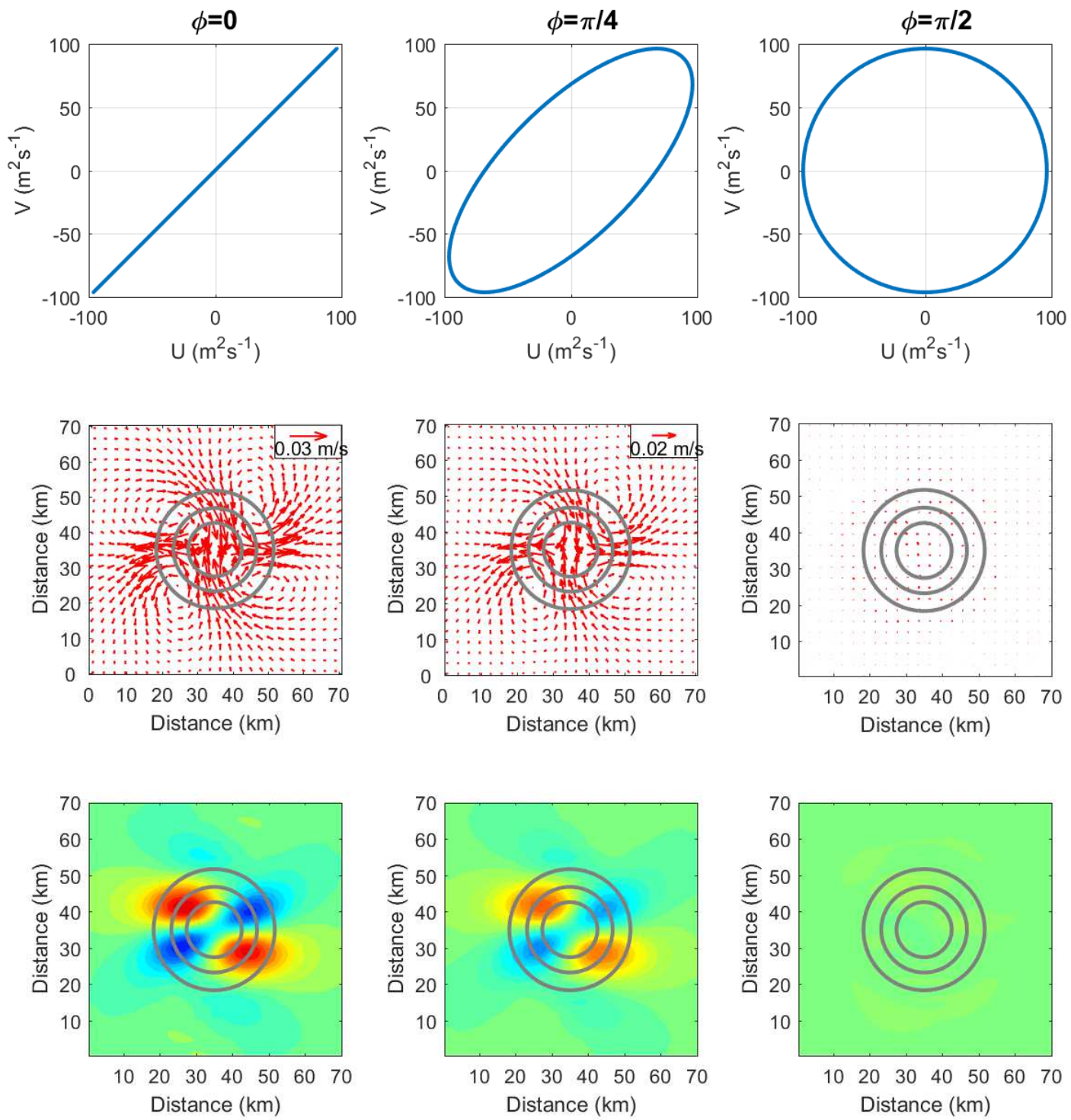

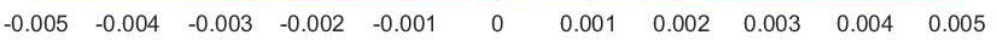

Figure A.1. Residual currents generated by tide over the Gaussian bank (A1) for $A=B=$ $100 \mathrm{~m}^{2} \mathrm{~s}^{-1}$ and $\phi=0$ (left column), $\phi=\pi / 4$ (middle column), and $\phi=\pi / 2$ (right column). Top row shows the tidal ellipses expressed in terms of water discharge. Middle panels represent the spatial distributions of residual currents. Bottom panels depict the vorticity $u_{y}-v_{x}\left(\mathrm{~s}^{-1}\right)$. 



Figure A.2. Spatial distribution of residual currents shown by arrows overlaid with the vertical velocity at the depth of $600 \mathrm{~m}$ obtained for homogeneous (a) and stratified (b) fluids. 
Table 1. Moorings

\begin{tabular}{lllcc}
\hline Mooring & Longitude & Latitude & Water depth $(\mathrm{m})$ & Frequency $(\mathrm{kHz})$ \\
\hline M1 (up) & $11^{\circ} 10.352^{\prime} W$ & $57^{\circ} 35.803^{\prime} \mathrm{N}$ & 770 & 75 \\
M1 (dn) & $11^{\circ} 10.352^{\prime} W$ & $57^{\circ} 35.803^{\prime} \mathrm{N}$ & 780 & 600 \\
M2 (up) & $11^{\circ} 11.250^{\prime} W$ & $57^{\circ} 37.242^{\prime} \mathrm{N}$ & 1160 & 75 \\
M2 (dn) & $11^{\circ} 11.250^{\prime} W$ & $57^{\circ} 37.242^{\prime} \mathrm{N}$ & 1170 & 600 \\
\hline
\end{tabular}

Table 2. Positions of the ROV dives

\begin{tabular}{lllc}
\hline Dive & Longitude & Latitude & Water depth $(\mathrm{m})$ \\
\hline 270 & $11^{\circ} 16.062^{\prime} W$ & $57^{\circ} 35.838^{\prime} \mathrm{N}$ & 826.8 \\
271 & $11^{\circ} 14.388^{\prime} W$ & $57^{\circ} 36.504^{\prime} \mathrm{N}$ & 928.3 \\
272 & $11^{\circ} 10.980^{\prime} W$ & $57^{\circ} 26.98^{\prime} \mathrm{N}$ & 645.2 \\
296 & $11^{\circ} 13.590^{\prime} W$ & $57^{\circ} 36.66^{\prime} \mathrm{N}$ & 1065.2 \\
\hline
\end{tabular}

